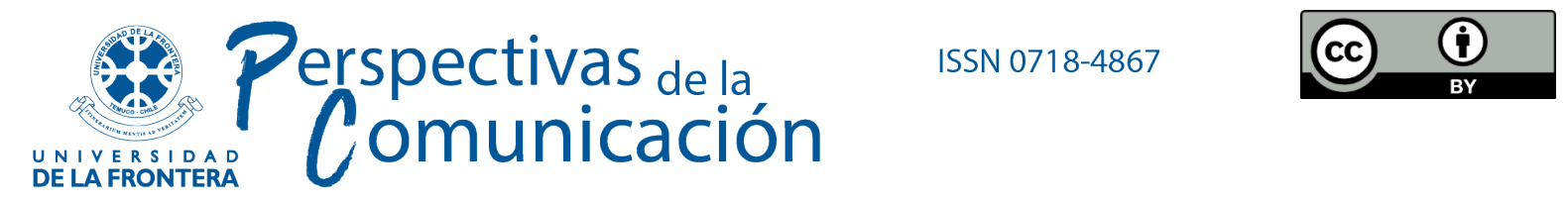

Artículo

\title{
EL DISCURSO BIOGRÁFICO SOBRE GABRIELA MISTRAL EN TORNO A SUS IMÁGENES
}

DOI: POR ASIGNAR

\author{
Mg. Horacio Alejandro Arros-Aravena \\ Universidad del Bio-Bío, Chillán, Chile \\ aarros@ubiobio.cl \\ ORCID iD: https://orcid.org/o0oo-0002-2393-5445 \\ Mg. Gabriel Farías Rojas \\ Universidad Adolfo Ibáñez, Chile \\ Universidad de Santiago de Chile \\ gabrielfariasrojas@gmail.com \\ Dra. Victoria Esgueva López \\ Universidad Politécnica de Valencia, España \\ Centro de Investigación de Arte y Entorno, UPV \\ maeslo2@dib.upv.es \\ Mg. Cristian Parra Bravo \\ Pontificia Universidad Católica de Chile \\ cfparra2@uc.cl
}

Recibido el 2021-04-29

Revisado el 2021-09-28

Aceptado el 2021-09-29

Publicado el 2021-12-14

\section{Resumen}

El objetivo de este artículo es establecer un recorrido semiótico del relato canónico de Gabriela, el cual se ha instalado oficialmente para corroborar el relato escritural de la vida la autora, sin dejar de establecer un recorrido paralelo tanto de imágenes rebeldes que ayudan a descentrar el primer relato desde aristas diferentes y refractarias de Mistral. Asimismo, se hace imprescindible dar cuenta de un tercer recorrido de imágenes post 
mortem sobre Gabriela Mistral, las cuales desde la libertad creativa de quienes las manipulan y publican, pueden llegar a otros entendimientos sobre Mistral, los cuales no necesariamente guardan relación con la vida canónica y rebelde de la autora. Para dicha categorización y análisis, fue menester contar con la teoría de Paleotti (2002) sobre las imágenes divinas y profanas, para luego añadir este tercer momento. Los resultados, además de mostrar recorridos semiótico-biográficos sobre la poeta, también dan cuenta de un itinerario de imágenes existentes y que han sido casi nulamente estudiadas, centrándose los estudios biográficos sobre ella principalmente en aspectos de su escritura.

Palabras clave: imágenes, Gabriela Mistral, imaginario, fotografía. 


\title{
A BIOGRAPHICAL DISCOURSE ON GABRIELA MISTRAL AS REPRESENTED BY IMAGES ABOUT HER
}

\begin{abstract}
The objective of this article is to establish a semiotic journey of Gabriela's canonical account, which has been officially installed to corroborate the written versions of her biography; this is done without ignoring a parallel journey of rebellious images that help decentralize the first traditional life-based account from different perspectives. Likewise, it is essential to give an account of a third tour of post-mortem images of Gabriela Mistral, which, from the creative freedom of those who manipulate and publish them, can lead to other understandings about Mistral, given the fact that they are not necessarily related to Mistral's either canonical life or rebellious life. For this categorization and analysis, it was necessary to focus on Paleotti's theory (2002) of divine and profane images, and then add this third moment of a series of images shown after Mistral's death. The results, in addition to showing semiotic-biographical journeys about the poet, refer to an existing itinerary of images that has been almost overlooked, as biographical studies have been mainly focusing on written aspects to provide an account of Gabriela Mistral's biography.
\end{abstract}

Keywords: images, Gabriela Mistral, imaginary, photography. 


\section{Introducción}

Gabriela Mistral sigue siendo una figura desconocida para la mayoría de la población chilena, a pesar de que hay ciudadanos en Chile que la creen como una importante poeta nacional ${ }^{1}$, sólo debido a sus Premios Literarios Nobel y Nacional, y gracias a sus poemas para niños y para la educación escolar primaria. Sin embargo, hay mucho más por saber. En este sentido, nos interesa la problemática de la universalización metonímica de Gabriela Mistral, que transita desde su postura de vida global y diversa a una consideración biográfica tradicional de madre y educadora. Lo anterior no hizo sino esconder durante mucho tiempo su naturaleza libre, pensante y hasta contradictoria, como correspondería a cualquier ser humano que piensa, opina y varía sus reflexiones y opiniones, con base en sus experiencias y cronología. Básicamente, esta subjetividad de Mistral se ha subsumido al servicio de una cultura occidental rígida que, al parecer, responde a ciertas estructuras sociopolíticas.

En este artículo, seguiremos una trayectoria a través de la constitución del mito fundador sobre la figura pública de Gabriela Mistral. Pretendemos mostrar la importancia de recordar el relato tradicional republicano sobre la vida de Gabriela Mistral, que comenzó con el mito de la madre de Chile, una mujer conservadora preocupada por la educación de los niños para servir a la República. En este sesgo, se comprende una biografía estática, basada en un mito que no solo se establece a través de la razón, sino como una imposición: primero por el republicanismo universal, que monumentalizará a Mistral como poeta; y luego por el gobierno de facto y militar de Augusto Pinochet, que consolidará la imagen de una apolítica Gabriela Mistral. Es menester también indicar que los gobiernos democráticos que se han sucedido desde principios de la década de los 90, tampoco han hecho un gran esfuerzo por liberar el mito consolidado en épocas anteriores. Muy por el contrario, han optado por un sutil y cómodo apego a la tradición.

Sin embargo, el relato escritural estático sobre la vida de Mistral no ha sido el único. Este se ha visto acompañado y reforzado por una serie de imágenes bienvenidas en Chile durante el período en el cual se encontraba viva tanto dentro como fuera del país; imágenes censuradas, es decir, aquellas imágenes que no encajaban con el ideal republicano y con el concepto de

${ }^{1}$ Utilizamos el término "poeta" en lugar de "poetisa" debido a la carga negativa del segundo significado en términos de igualdad entre hombres y mujeres en la literatura. 
mujer abrazado por el discurso hegemónico; y todo ese cúmulo de imágenes post mortem en el cual se aprecia una ideología refractaria al modelo republicano, cuya supuesta intención inicial es liberar a Gabriela Mistral del relato positivista que de ella se ha hecho en Chile; no obstante aquello, al contener estrategias de efecto político, dichas imágenes terminan sirviendo más a los intereses de quienes las manipulan, pudiendo llegar a jugar literalmente con la corporalidad mistraliana, y no necesariamente responden a la imagen que la poeta y escritora quiso proyectar de si misma y que discurseó en sus variados ensayos y conferencias. Además, en ello está presente una lectura contemporánea de diversos tópicos que tiende a ser anacrónica con la postura real de Gabriela Mistral en el tiempo en el cual escribió y desde y sobre los lugares que lo hacía. De esta manera, en este complejo escenario es que nos interesa lidiar con este discurso en torno a las imágenes de Gabriela, el cual puede reforzar el mito mistraliano, rechazarlo de plano o alterarlo de manera insospechada.

En torno a las tres formas discursivas sugeridas por los grupos de imágenes referidos arriba, es que nos hacemos la siguiente pregunta de investigación: ¿Cómo surgieron tres grandes relatos sobre Gabriela Mistral durante su vida y posterior a ella en torno a sus imágenes propias o imágenes sobre ella? Para responder inicialmente a dicha pregunta nos planteamos la siguiente hipótesis que intentaremos confirmar a lo largo de este artículo: El relato de la vida de Gabriela no es sólo escritural, sino que también es semiótico y ha influido sobremanera en la construcción del mito mistraliano canónico y republicano al mismo tiempo que en la construcción de un sujeto escindido entre el deber ser y otro que corresponde a aquello que la poeta y escritora no fue pero que podría haber sido. Por una parte, esto ocurre gracias a una cuidadosa selección de imágenes que adscriben al status quo y, por otro lado, aparecen otros dos relatos: El primero se presenta a modo espectral como el conjunto de imágenes rebeldes y censuradas de Mistral que no vienen a tomar relevancia pública sino recién en la últimas décadas; por otra parte existe otro acervo de imágenes con una carga ideológica externa que se configura a partir de una manipulación explícita de la corporeidad mistraliana, un poco ajena a los hechos reales en sí.

Con el objetivo de resolver nuestra hipótesis recurrimos al gran teórico del Discurso en torno a las imágenes sagradas y profanas, Paleotti (2002), quien inicialmente publicaría su tratado en el año 1582. Además de ser el gran teórico que se preocupó de generar una tipología de las imágenes con respecto al discurso que semióticamente enuncian, a partir de una base sagrada y una contraparte profana, su punto de partida se condice con la imagen canonizada de Gabriela Mistral en el Chile republicano que se enlaza con este relato maternal, 
pedagógico y de poetisa infantil, junto con el grupo de imágenes que responden al ideario de mujer republicana, esto es, una que corra por el camino paralelo al del hombre y no disputa su espacio público. A su vez, propone otro grupo de imágenes, que tomaremos como tercer grupo en esta investigación, de verosimilitud compleja. Por lo mismo, creemos posible corroborar nuestra hipótesis al proponernos el siguiente objetivo general para nuestro trabajo: Seleccionar aleatoriamente, desde fuentes de internet, imágenes de Gabriela Mistral para luego ordenarlas de acuerdo con tres de las categorías referidas por Paleotti (2002) y que representarían, en términos generales, las tres principales formas en que se ha representado el relato biográfico de Gabriela Mistral en Chile.

El orden de este artículo corresponderá a explicitar por una parte el relato escritural tanto canónico como alternativo de Gabriela Mistral en Chile y luego, desde un análisis de una selección de imágenes, conforme a las categorías de Paleotti (2002), entender el discurso imaginario a través de las dos categorías que relatan la vida de Gabriela Mistral en vida, sumando una tercera lectura postmoderna que da cuenta de una Mistral que escapa a su posibilidades en vida y que se constituye en torno a un cruce entre su aparente enunciación en vida y la de aquellas/os que pretenden representarla en la actualidad.

\section{Revisión de la Literatura: El desafio de entender a Mistral}

El reconocimiento nacional de Gabriela Mistral no llegó cuando recibió el Premio Nobel de Literatura, sino solo después de obtener el Premio Nacional de Literatura en 1951. Autora de poesía y prosa, no solo es el primer Premio Nobel de Literatura para Chile, sino que se convirtió en la primera persona en recibir dicho reconocimiento en Iberoamérica en 1945.

Mistral proviene del mundo rural. Nació en la ciudad de Vicuña en 1889 y murió en los Estados Unidos, Nueva York, distrito de Long Island en 1957. La Academia Sueca señaló que se le otorgó el Premio Nobel de Literatura por “... su poesía lírica inspirada en poderosas emociones y por haber hecho de su nombre un símbolo de las aspiraciones idealistas de todo el mundo latinoamericano." (Quezada, 2014, p. 10) Sus libros más importantes durante el tiempo que estuvo viva, según el crítico literario Jaime Concha, son "Desolación, Ternura, Tala y Lagar" (2015, p. 59). El primero de ellos se publicó en el Instituto Español de Nueva York en 1922. El segundo se publicó en Madrid, España en 1924. El tercero se publicó en Buenos Aires en 1938. Y finalmente, el último de ellos, Lagar, publicado en Santiago de Chile en el año 1954. Después de su muerte, se publicó el Poema de Chile en Barcelona, España, en el año 1967. 
En Desolación, Jaime Quezada (2014) afirma que "más que amargos, los poemas de este libro tienen el verso íntimo, conversacional y emotivo, desvelado de éxtasis e interrogaciones en humano tratamiento de existencia y vida, situaciones que darán huella y carácter a esta obra, después de todo, reveladora de amores y celos y romanticismo.” (p. 11). Sin embargo, ¿hasta qué punto es posible analizar el dolor de Mistral en este libro sin caer en una fusión exagerada de la vida y obra? En esta perspectiva, Jaime Concha expresa que "sin duda, la leyenda del enamorado suicida - ese ferroviario que se destapó las sienes por razones de dinero - ha perjudicado y deformado la imagen de esta poesía. Los Sonetos de la Muerte, que poco tienen que ver en el fondo con esa leyenda, han contribuido a consolidar esa imagen de turbia pasión, de halo más bien sensacionalista”. (Concha, 2015, p. 55)

Diego del Pozo (2015a), además de estar de acuerdo con la opinión de Concha, quien considera la muerte del suicida (Romelio Ureta) como el gran dolor e inspiración de la Desolación, entiende que esta tragedia sirve de inspiración para los "Sonetos de la muerte" (1914), como “... el principio de una larga lista de pérdidas de grandes amores; humanos, divinos, íntimos, históricos y ficticios” (Pozo, 2015a, p. 27).

Jaime Concha, por otro lado, entiende este dolor como un motivo creativo y puede no ser el único. Debido a esto, este dolor no es la única causa y explicación de los "Sonetos de la muerte". Por lo tanto, nuestra visión ${ }^{2}$ va en armonía con las posturas de Concha y Claudia Cabello Hutt (2015), quien, refiriéndose a Jaime Concha, reflexiona:

El crítico se enfrenta a ella con independencia, escuchándola, rechazando mitos y lugares comunes", como, por ejemplo, "las lecturas de victimización que han visto las tragedias de la vida de Mistral como inspiración directa de sus poemas. El ejemplo más común es el caso del suicidio de Romelio Ureta y los "Sonetos de la Muerte", mito que el mismo Concha rechaza. (p. 15-16).

Ternura, el libro que tuvo ediciones futuras, especialmente a partir de 1945, presenta el famoso poema "Piececitos de Niño", que fue fundamental para el conocimiento de Mistral en Chile, sobre cuya base intencional descansaba el mito que se generó en el Chile republicano en el siglo XX. Con respecto a este libro, Mistral dice:

${ }^{2}$ Tomamos una perspectiva menor desde una autobiografía mítica, monolítica y más global del proceso creativo de Mistral.

Perspectivas de la Comunicación - Vol. 14 - No 2 - 2021 - pp. 127-148

Universidad de la Frontera - Chile 
Cuando he escrito una ronda infantil, mi día ha sido verdaderamente bañado de Gracia, mi respiración como más rítmica y mi cara ha recuperado la risa perdida en trabajos desgraciados. Tal vez el esfuerzo fuese el mismo que se puso en escribir una composición de otro tema, pero algo, que insisto en llamar sobrenatural, lavaba mis sentidos y refrescaba mi carne vieja. (Quezada, 2014, p. 11 - 12)

Un poema conocido y representativo del libro Ternura es Miedo. En él, la poeta habla sobre la importancia de la infancia de los niños como un espacio de simplicidad y creatividad, lejos del mito de la princesa, que prohíbe a una niña vivir una infancia simple y cerca de su madre. Es una mezcla entre un sentido de protección de la maternidad y al mismo tiempo garantizar la libertad del niño, que no debe estar sujeto a los estándares establecidos para las mujeres, como la opinión de que una princesa debe alejarse del mundo natural 3 - mundo natural como se entiende en la Dialéctica de la Iluminación (Adorno y Horkheimer, 2007), es decir, sin reglas-para responder a lo que la sociedad espera de ella. El poema extendido dice así:

\author{
Yo no quiero que a mi niña \\ golondrina me la vuelvan; \\ se hunde volando en el Cielo \\ y no baja hasta mi estera; \\ en el alero hace nido \\ y mis manos no la peinan. \\ Yo no quiero que a mi niña \\ Golondrina me la vuelvan. \\ Yo no quiero que a mi niña \\ la vayan a hacer princesa. \\ Con zapatitos de oro \\ ¿cómo juega en las praderas? \\ Y cuando llegue la noche \\ A mi lado no se acuesta. \\ Yo no quiero que a mi niña \\ La vayan a hacer princesa. \\ Y menos quiero un día \\ me la vayan a hacer reina.
}

\footnotetext{
3 De esta manera, el mundo natural, es decir, la naturaleza, con sus variables ilimitadas, es rechazada por la ciencia por su anarquía, la cual no es sujeto de control por parte del ser humano.
} 


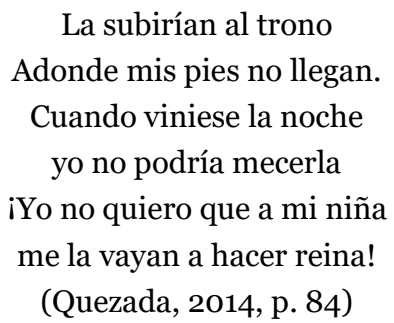

El libro Tala es considerado por los críticos e incluso por ella misma como su obra más importante, "... sobre todo porque en sus páginas está la raíz de lo indoamericano" (Quezada, 2014, p. 12). Saudade, la palabra que usa en portugués, denota el período de escritura de libros en el que Mistral frecuentaba varios lugares de América y Europa en su autoexilio de Chile (Quezada, 2014). Sin embargo, Tala se considera un libro complejo y difícil de analizar en comparación con Desolación. (Concha, 2015)

Entre las piezas americanas en Tala, uno de los poemas más destacados que dará cuenta de una Mistral más centrada en un espíritu latinoamericano es el poema Sol del Trópico. El mayor rescate encontrado es el de los pueblos precolombinos juntos en un solo himno. Aquí el sentimiento latinoamericano es similar a esta mitología común que Claude Levi-Strauss (2010) busca tan apasionadamente en los pueblos indígenas de América. El espíritu indigenista latinoamericano de Mistral se consolida desde su estadía en el México postrevolucionario.

Lagar fue escrito dieciséis años después de Tala. El concepto de guerra, y particularmente la Segunda Guerra Mundial, es una fuente de inspiración y manifestación creativa. Quezada (2014) dice que "un aire denso y sucio mancha los cielos de la humanidad. Y mientras suena el infierno de los tanques y caen los aviones en sesgo de vergüenza, Gabriela Mistral escribe su manifiesto por la causa de la paz...” (p. 14). De hecho, el período de Lagar y la prosa de la década de 1950 es el de una voz que clama por la paz mundial. Así, por ejemplo, Jaime Concha (2015) escribe que Lagar es el libro de poesía donde Mistral obtiene "su más decantada expresión" (p. 57). La madurez de la escritora, que tiene como fuente de inspiración todo lo que había vivido y escrito hasta ese momento, convirtió a Lagar en un libro de consolidación de su escritura subjetiva, intersubjetiva y librepensadora antes de su muerte en 1957. 
Un poema importante de Lagar es La muerte del mar. Una selección del poema es la siguiente:

\begin{abstract}
Se murió el mar una noche
de una orilla a la otra orilla;

se arrugó, se recogió,

como manto que retiran.
\end{abstract}

\section{(...)}

Los pescadores bajamos

a la costa envilecida, arrugada y vuelta como la vulpeja consumida.

$$
\begin{gathered}
\text { (...) } \\
\text { Pescadores de ojos fijos } \\
\text { le llamamos todavía, } \\
\text { y lloramos abrazados } \\
\text { a las barcas ofendidas. } \\
\text { Y meciéndolas, meciéndolas, } \\
\text { tal como él se las mecía, } \\
\text { mascamos algas quemadas } \\
\text { vueltos a la lejanía, } \\
\text { o mordemos nuestras manos } \\
\text { igual que esclavos escitas. } \\
\text { Y cogidos de las manos } \\
\text { cuando la noche es venida } \\
\text { aullamos viejos y niños } \\
\text { como unas almas perdidas. } \\
\text { iTalassa, viejo Talassa...! } \\
\text { (Concha, 2015, p. 58-59) }
\end{gathered}
$$

Con respecto al poema citado anteriormente, Concha (2015) afirma que "pocas veces la poesía lírica puede alcanzar este sentido cosmogónico, esta vasta ojeada metafísica a la realidad. Y unir, ahora, el símbolo metafísico con la profecía histórica” (p. 59). Y esta es básicamente la importancia del trabajo poético y en prosa de Gabriela Mistral, que se puede releer a la luz de los acontecimientos actuales. 
Un regalo que recibió Chile, a pesar de la indiferencia sufrida por Mistral en su propio país, es el libro póstumo llamado Poema de Chile, que se publicó en Barcelona, España, en el año 1967. Esto llevará a un camino espiritual la escritura de Mistral, basado en sus experiencias de viajes pasados por todo Chile y su fuerza creativa de un viaje por Chile con una descripción poética y caracterización del país que resultó ser una verdadera disculpa para la nación que la poeta amaba míticamente. Sobre el libro Poema de Chile, Jaime Quezada (2014) dice lo siguiente:

La autora se hace acompañar aquí de un niño atacameño y diaguita, además de un huemulillo o ciervo chileno, en un recorrer el territorio patrio en su extensa y larga geografía: su naturaleza física y humana, sus valles y sus ríos, su cordillera andina y sus metales, su desierto y su mar, su flora y su fauna, sus archipiélagos australes y su extensa y verde Patagonia. Lo vivo y lo viviente del suelo natal en un redescubrir la entraña misma del largo país. (p. 15)

El libro se presenta como la aporía de Gabriela Mistral en la relación con su país. El mismo país del que se fue, también representa un profundo amor que le tiene a la geografía nacional y sus raíces en las cuales se presenta a sí misma como americana y mestiza. En este punto, un poema interesante, que se explicará después de su presentación aquí es "Montañas mías":

\footnotetext{
En montañas me crie Con tres docenas alzadas.

De hecho, las montañas que nunca dejaron a Mistral, y que tuvo que abandonar después de su autoexilio para liberarse de la opresión, la mezcla de desprecio por su figura y la 
imposición en una construcción mítica republicana que no era la suya, significaban para ella una nostalgia eterna en este constante recorrer por los países que visitó la poeta y escritora. 4

Por lo tanto, este abandono que Mistral hace a las amadas montañas de su Chile tiene la intención de liberarse de la opresión del mito que de ella se estaba creando en Chile y que, indirectamente, la forzaba a abrazar, ante la imposibilidad de estar eternamente desmintiéndolo. ${ }^{5}$ Es por este contexto que la mayoría de su prosa no se considera en la consolidación posterior del mito colonizador que se hace de ella. Su prosa desafiaría este status quo, por lo que no tenía posibilidad de continuar siendo aceptado en una sociedad cuyas expectativas eran de una mujer servil y madre eterna -sinónimo de feminista Amanda Labarca y retomado por Alejandra Castillo (2014) para explicar una idea tradicional de mujeres asociadas y restringidas solo a la familia y la maternidad -, prototipo la educadora republicana de la nación.

\section{Método}

Para problematizar los tres grandes grupos de imágenes en torno al discurso sobre la vida de Gabriela Mistral, haremos referencia a tres conceptos de Gabriele Paleotti (2002) tomados de su tipología de los tipos de imágenes sagradas y profanas. Así, de acuerdo a este teólogo que teoriza sobre las imágenes sagradas y profanas, una imagen sagrada será santa en la medida en que cuenta en ella con una persona santa. Esto no es aplicable literalmente, aunque sí figurativamente en el caso de Gabriela Mistral, quien fuera, según la crítica, canonizada tempranamente a partir de biografías tales como La Divina Gabriela, e incluso Santa Gabriela, de manera de colocar a Mistral en el ideario de la mujer ejemplo para una república (Concha, 2015). La imagen profana, por otra parte, tal como establece Paleotti (2002), se definirá en oposición a la imagen sagrada, es decir, invirtiendo el valor de lo sagrado, o canónico -figurativamente- en el caso de Mistral, y lo transforma en "cosa impura" (Paleotti, 2002, p. 43). Esto no es extraño al ver las imágenes de Gabriela Mistral que

\footnotetext{
4 Utilizamos los nombres de poeta y escritora para reconocer a Gabriela Mistral, por sus producciones poéticas y prosaicas, esta última muy censurada, especialmente su prosa política.

${ }_{5}^{5}$ Esto no significa que las montañas la hayan encarcelado. Tuvo que irse de Chile, y el costo desagradable de esa decisión fue abandonar las montañas.
} 
consideraremos profanas, las cuales se ignoran, a modo de censura no explícita, puesto que opacarían el halo de pureza que rodea a la imagen mistraliana republicana.

\subsection{Categorización de las imágenes}

En términos generales, las imágenes serán consideradas en tres grandes grupos: (i) sagradas y (ii) profanas, ambas se relacionan directamente con las imágenes verdaderas de Gabriela Mistral y que fueron tomadas durante el período en que se encontraba viva; y (iii) post mortem, que corresponden a alteraciones del relato mistraliano a través de imágenes manipuladas posterior al año de su muerte, en 1957; estas últimas producidas con el objetivo de hacer uso del peso político de la autora con fines ideológicos a los que, supuestamente, habría adscrito la poeta en vida.

En términos específicos, se hará una reflexión sobre cada imagen en particular en torno a tres ejes principales: época a la que supuestamente pertenece la fotografía, contexto el que cual se publica dicha imagen en la fuente a la que se hace referencia en cada caso en este trabajo, y cómo se justifica la consideración de cada imagen con respecto a las categorías centrales de distribución de las imágenes de Gabriela Mistral desarrolladas en esta investigación. La tercera clasificación de las imágenes aquí tratada no se define categorialmente por Paleotti, pero hace referencia a ello estableciendo un tipo de imagen cuya verosimilitud es compleja tomando en consideración las características del diseño que la componen. En este contexto, podemos considerar un conjunto de imágenes post mortem de Gabriela Mistral, en la cual hay imágenes de plano alteradas desde el diseño y la representación artística o reales, pero colocadas en un plano discursivo que escapa al contexto original, es decir, son parte de un nuevo relato que no puede completamente asemejarse a la fuente original.

\section{i. Imágenes canónicas de Gabriela Mistral}


Figura 1. Captura de documental de "Historias de Vida

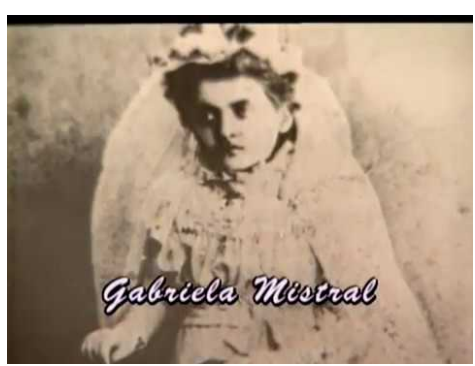

Fuente: https://images.app.goo.gl/KHkCXofaTXKysY2LZ, año 2020.

a) Época de la imagen (Figura 1): Corresponde al período en que vivía en Vicuña, cuando aún no era Gabriela Mistral y era conocida localmente como Lucila Godoy Alcayaga.

b) Contexto de publicación de la imagen: La imagen es un rescate de Google del documental del YouTube titulado Historias de vida - Gabriela Mistral.

1) Justificación de la imagen con respecto a la categoría en la cual se considera: Es una imagen de carácter religioso, tal como se hace alusión en el documental. Lo más probable es que sea de su Primera Comunión, lo cual la hace canónica si consideramos la todavía colación entre la Iglesia y el Estado en el período en que se toma la imagen y durante las primeras dos décadas del siglo XX.

Figura 2. Fotografía de Gabriela Mistral en sitio de la Universidad de Chile.

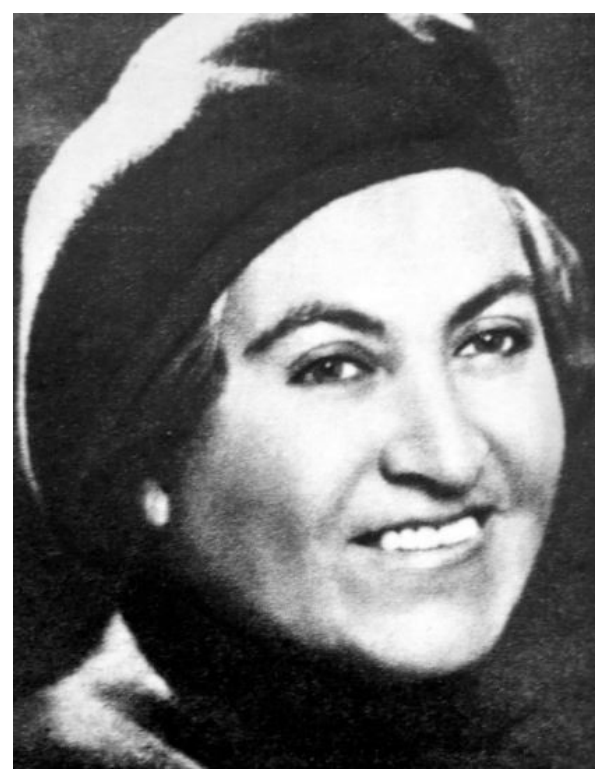

Fuente: https://images.app.goo.gl/Tcw7Y2qceVgUYNhw5, año 2020.

a) Época de la imagen (Figura 2): Esta imagen corresponde a la época de juventud de Gabriela, en la cual ejercía como profesora de escuela en Chile.

b) Contexto de publicación de la imagen: Imagen publicada en el sitio web de la Universidad de Chile, en el cual se entrega información sobre los premios nacionales de literatura. 
1) Justificación de la imagen con respecto a la categoría en la cual se considera: Es una canónica puesto que calza con la imagen de educadora perenne que se pretende fijar en la vida de Gabriela Mistral en el Chile republicano.

Figura 3. Fotografía referente a la noticia de la BBC "La prefieren loca que lesbiana".

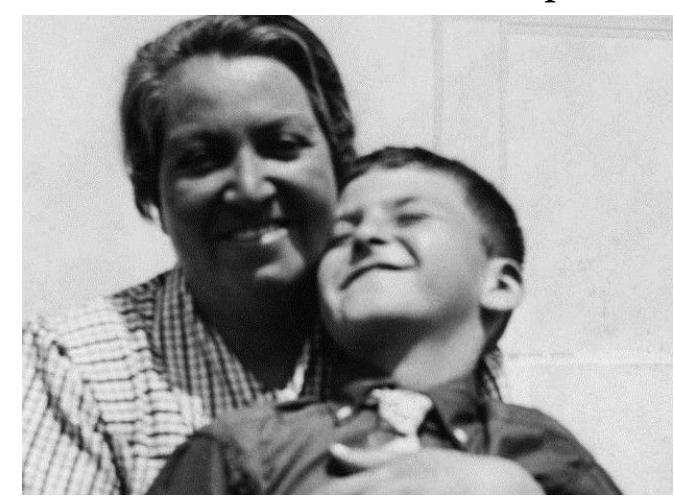

Fuente: https://images.app.goo.gl/WUUqcRHvVeUPBbKRq, año 2020.

a) Época de la imagen (Figura 3): Esta imagen corresponde a la vida de juventud entrando en la madurez de Gabriela Mistral, probablemente antes de asentarse en Brasil en la década de 1940. Quizás esta imagen corresponde a la década anterior, cuando junto a su hijo vivían en Europa.

b) Contexto de publicación de la imagen: Esta imagen es mostrada de manera aleatoria en el contexto de una noticia sobre Gabriela Mistral en la BBC de un tema que no guarda relación con el billete, su supuesto lesbianismo. Sin embargo, al ser una de las imágenes republicanas más importantes de la poeta, lo más probable es que se decida colocarla junto a las otras imágenes que acompañan la noticia.

1) Justificación de la imagen con respecto a la categoría en la cual se considera: Es una canónica puesto que calza con la imagen de madre, junto a la de educadora, que se pretende fijar en la vida de Gabriela Mistral en el Chile republicano. 
Figura 4. Entrega Premio Nobel de Literatura, en el sitio de la Universidad de Chile.

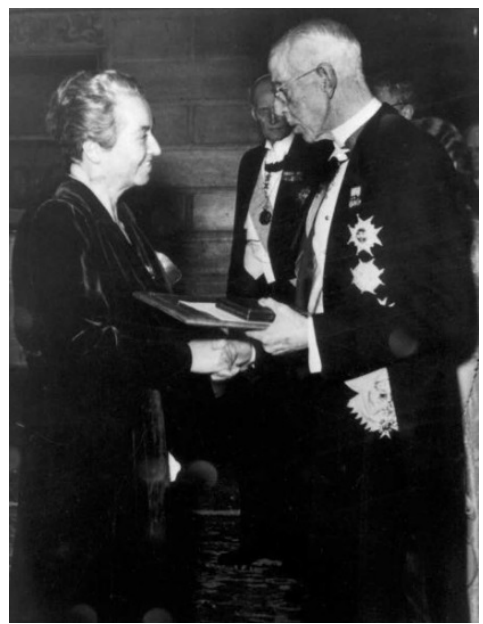

Fuente: https://images.app.goo.gl/MmK2TTTykmyqPPby5, año 2020.

a) Época de la imagen (Figura 4): Corresponde a la ceremonia de entrega a Gabriela Mistral del Premio Nobel de Literatura por parte de la Academia Sueca en 1945.

b) Contexto de publicación de la imagen: Imagen publicada en el sitio web de la Universidad de Chile, en el cual se entrega información sobre los premios nacionales de literatura.

1) Justificación de la imagen con respecto a la categoría en la cual se considera: Esta imagen canónica de manera universal irrumpe forzosamente en el imaginario republicano chileno sobre Gabriela Mistral ya que se constituye en una sorpresa para Chile, país en el cual sólo año después se le concedería el Premio Nacional de Literatura. Aparentemente, se establece una aporía entre el éxito a nivel de un espacio educativo y maternal al cual se había confinado republicanamente a Mistral y la obtención del Premio Nobel de Literatura, en el cual ella destacaba por sobre los hombres de la República de Chile.

\section{ii. Imágenes profanas de Gabriela Mistral}


Figura 5. Captura de pantalla del documental "Grandes Chilenos", emitido por Televisión Nacional de Chile.

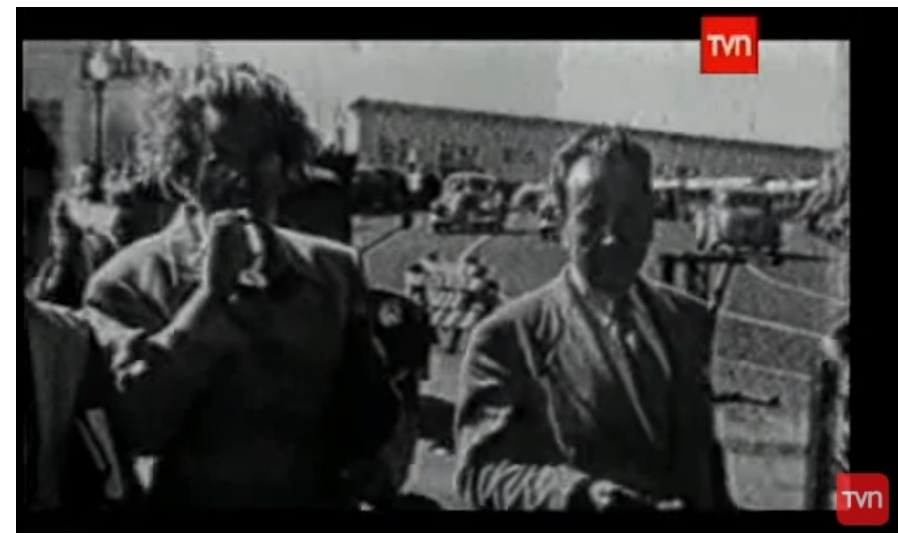

Fuente: https://youtu.be/xqIwLnnPcKU, año 2020.

a) Época de la imagen (Figura 5): Madurez de vida de Gabriela Mistral. Se desconoce exactamente el año y lugar de toma de la fotografía.

b) Contexto de publicación de la imagen: Es una imagen que los autores de este artículo toman a partir del documental de Gabriela Mistral que se emite en el programa del canal de televisión TVN (Televisión Nacional de Chile), llamado Grandes Chilenos, y publicado en el canal de YouTube de este.

1) Justificación de la imagen con respecto a la categoría en la cual se considera: Esta imagen se presenta como una imagen profana puesto que no calza con la pureza destinada al canon mistraliano republicano. Se muestra una mujer que no adscribe a la feminidad que se espera de ella, ya que se encuentra públicamente despeinada y fumando en la vía pública. Con respecto al vestuario, se aprecia, también, una chaqueta y no un tan bien valorado vestido en la época en que se toma la fotografía, es decir, antes de la década del 60 en el siglo 20.

Figura 6. Fotografía de Gabriela Mistral y Doris Dana publicada en el periódico digital “El Desconcierto".

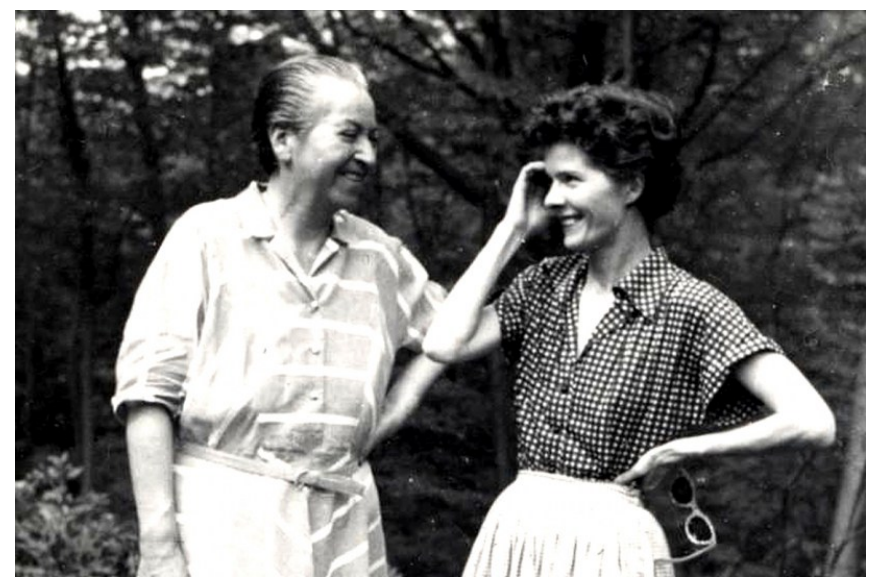

Perspectivas de la Comunicación - Vol. 14 - No 2 - 2021 - pp. 127-148 Universidad de la Frontera - Chile 
Fuente: https://images.app.goo.gl/9xY6xy7FMu6HWrxM7, año 2020.

a) Época de la imagen (Figura 6): Madurez de vida de Gabriela Mistral. Época en que compartía con Doris Dana.

b) Contexto de publicación de la imagen: Es parte de un artículo periodístico del diario chileno El Desconcierto, en el cual se pretende evidenciar una relación de amor entre Gabriela Mistral y Doris Dana.

1) Justificación de la imagen con respecto a la categoría en la cual se considera: Esta imagen se presenta como una imagen profana puesto que, si bien originalmente no se relaciona directamente con el supuesto lesbianismo de Mistral, en la época en que se toma la fotografía, se corresponde con una imagen del ámbito privado de Gabriela Mistral, el cual no interesa a la estructura discursiva republicana de la época en la que ella estaba con vida. Inmiscuirse en la vida privada de la autora sólo desviaría la atención de la imagen nacional que de ella se pretendía en Chile.

\section{iii. Imágenes post mortem de Gabriela Mistral}

Figura 7. Imagen de billete chileno de cinco mil pesos.

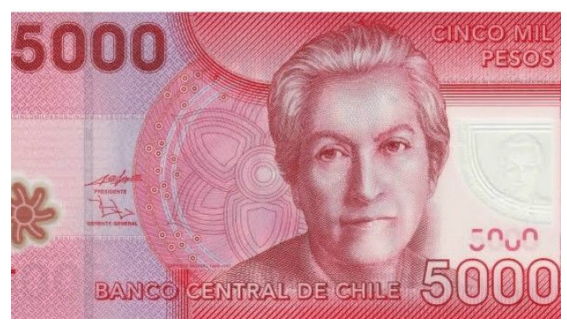

Fuente: https://images.app.goo.gl/nSCB.3qzE561szjC79, año 2020.

a) Época de la imagen (Figura 7): Esta imagen corresponde a la emisión del billete por parte del Banco Central de Chile en 1981.

b) Contexto de publicación de la imagen: Esta imagen es mostrada de manera aleatoria en el contexto de una noticia sobre Gabriela Mistral en la BBC de un tema que no guarda relación con el billete, su supuesto lesbianismo. Sin embargo, al ser una de las imágenes republicanas más importantes de la poeta, lo más probable es que se decida colocarla junto a las otras imágenes que acompañan la noticia.

1) Justificación de la imagen con respecto a la categoría en la cual se considera: Podríamos considerarla un puente entre una imagen canónica de Mistral y las sucesivas imágenes post mortem puesto que deliberadamente ya no por la mera selección de imágenes adecuadas al contexto republicano, se consolida una imagen de Gabriela Mistral que sea armónica a los intereses de la nación. Asimismo, la consideramos en el grupo post mortem por un tema cronológico ya que la escritora falleció en 1957. 
Figura 8. Fotografía de Gabriela Mistral.

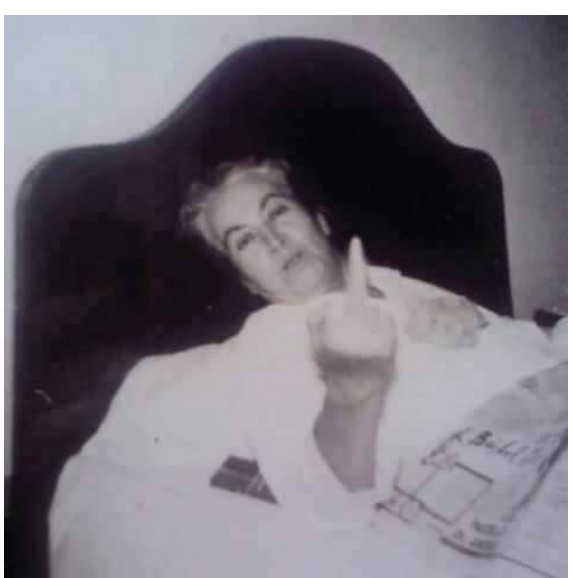

Fuente: https://images.app.goo.gl/giAiJPZPRNCym6rzq, año 2020.

a) Época de la imagen (Figura 8): Esta imagen, alterada posteriormente, quizás por algún programa computacional de edición de imágenes, corresponde a las postrimerías de la vida de Gabriela Mistral.

b) Contexto de publicación de la imagen: Esta imagen es publicada en un sitio web Tumblr de Mujeres Indígenas en la cual se pretende hacer un panegírico de la valentía de Gabriela con respecto a su supuesto lesbianismo. Decimos supuesto lesbianismo porque se da por hecho en la publicación de este sitio web y desde ahí se construye un relato en torno a su arrojo para afrontar dicha realidad.

1) Justificación de la imagen con respecto a la categoría en la cual se considera: Para comenzar, al ser una imagen alterada, una Gabriela Mistral levantando el dedo se constituye literalmente como una falacia, pero, al mismo tiempo, también en tanto metáfora para representar una actitud rebelde frente a un mundo que se opone a su supuesto lesbianismo. Esta imagen corresponde a una construcción simbólica que hace su verosimilitud un tanto difusa.

Figura 9. Fotografía junto a Doris Dana, aparecida en el portal noticioso de la BBC.

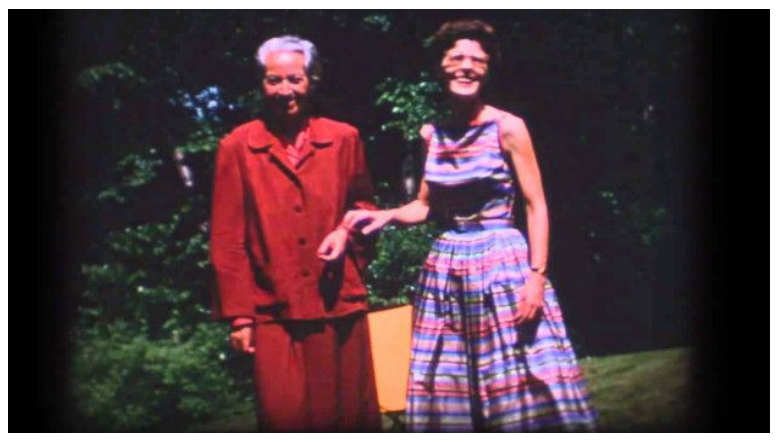

Fuente: https://images.app.goo.gl/khJbXTxKKeH7k2DN6, año 2020.

a) Época de la imagen (Figura 9): Esta imagen corresponde a las postrimerías de la vida de Gabriela Mistral, en la que ya compartía a tiempo completa con su compañera de vida Doris Dana. Como compañera, no asumimos ningún tipo de compañerismo en particular, sino sólo damos cuenta de una convivencia independiente de los términos en los que se diese. 
b) Contexto de publicación de la imagen: Esta imagen se publica en el contexto de una notica de la cadena $B B C$, en la cual se pretende abordar la sexualidad de la autora.

c) Justificación de la imagen con respecto a la categoría en la cual se considera: Si bien el origen de esta imagen es anterior a la muerte de Mistral, consideramos esta imagen dentro de la categoría post mortem puesto que esta imagen es mostrada en un documental llamado Locas Mujeres, de la directora María Elena Wood, en el cual se sugiere un lazo no heteronormativo entre la poeta y Doris Dana.

Figura 1o. Fotografía del mural de Gabriela Mistral en el Centro Cultural GAM en Santiago de Chile.

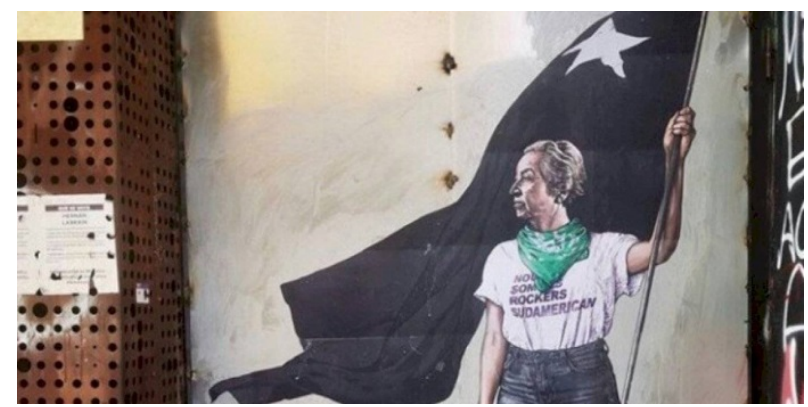

Fuente: https://images.app.goo.gl/qq9fT7oGov7qyGNQ7, año 2020.

a) Época de la imagen (Figura 10): Esta imagen es actual y corresponde a un mural en las afueras del Museo Gabriela Mistral (GAM).

b) Contexto de publicación de la imagen: Se publica recientemente, el 20 de noviembre de 2019, en el contexto de una noticia del diario chileno Publimetro, a raíz del mural de Gabriela Mistral en el GAM.

1) Justificación de la imagen con respecto a la categoría en la cual se considera: Este mural de Gabriela Mistral dice relación con el reciente estallido social de Chile el 18 de octubre de 2019 y a raíz del cual se representa una Gabriela Mistral con una bandera de luto de un Chile que se rebela, pero lo hace desde una postura enunciativa feminista, ya que viste jeans (los cuales no se condicen con la realidad de la poeta en la época que vivió) y el contemporáneo pañuelo verde que es parte del movimiento feminista mundial, con origen en el feminismo argentino. Aunque bien intencionada, esta imagen tomaría un camino paralelo a las posturas que Mistral toma con respecto al movimiento feminista de su época en su prosa, como por ejemplo en el ensayo titulado "La Organización de las Mujeres"6 (Pozo, 2015b). Asimismo, una conexión directa entre Gabriela Mistral y el feminismo de la Tercera Ola es anacrónica, por lo cual, dicha imagen se puede leer desde una intención de situar a la autora desde sus posturas autónomas en el contexto de las demandas sociales actuales.

${ }^{6}$ Citado en Por la Humanidad Futura, antología de la prosa de Gabriela Mistral. 


\section{Conclusiones}

Es interesante ver cómo tres grandes grupos de imágenes, que dan cuenta de la vida de Gabriela Mistral y que aparentemente corren en series paralelas, pueden confluir y desafiar la pretendida rigidez del relato de sus discursos. Ya en vida, se da una conexión inesperada entre una Gabriela Mistral canónica y una profana: en la primera debe asumirse una Mistral Nobel, como una imagen canónica, en un Chile que preferirá continuar representándola como profesora y poetisa de rondas infantiles en vez de una poeta completa y escritora autónoma, voz de una intelectual a nivel del continente americano y del mundo; esto último se relacionaría con el imaginario profano. Asimismo, el billete de cinco mil pesos se plantea como otro intento republicano de una manipulación post mortem de Gabriela, el cual, desde su afán de reforzar un imaginario republicano sobre la autora; sin embargo, esta imagen termina abriendo la posibilidad a un acervo de imágenes mistralianas que alterarán nuestras figuraciones sobre Mistral desde una multiplicidad impensada y siempre cambiante en la semiótica actual. Sin embargo, siempre, ante estos dos grupos que parecen imponerse en el imaginario colectivo mistraliano, aparecerá a modo espectral esa Gabriela Mistral censurada en su época y aún ignorada en la actualidad, tiempo en el que más parece importar lo que otras/os pretenden decir sobre ella que el cómo ella quiso representarse a sí misma.

Es aquella tensión entre una metonimia tradicional representada en forma de imágenes para dar cuenta de una biografía oficial de Gabriela Mistral y otra metonimia aparentemente reivindicativa de la poeta en la instalación contemporánea de la otredad la que sotierra ese relato biográfico quizás más propio de ella. Ahí donde las palabras son acalladas debido a relatos oficiales y refractarios de terceros -en ambos casos-, las imágenes parecen ser una vía de escape que muestran sucesos por decir, pero cuyo relato aún no se ha configurado lingüísticamente. En el caso de Mistral, hasta la actualidad una figura bastante desconocida a pesar de su fama, las imágenes, al carecer de signos lingüísticos, nos recuerdan que la realidad es más compleja que las meras palabras y que no todo puede ser completamente silenciado; las imágenes continúan ahí para representar aquello que no precisan decir, en este caso una Mistral potencial y hasta ahora no sujeto de intereses foráneos. De ahí el relato genuino que dichas imágenes nos cuentan/muestran es al mismo tiempo una invitación a la investigación y a la reivindicación de una Mistral menos coherente y, por lo mismo, mucho más creíble a los ojos de quienes la reciben, sea en sus palabras, sea en sus imágenes.

\section{Conflicto de interés:}

Los autores declaran que no existe conflicto de interés.

Perspectivas de la Comunicación - Vol. 14 - No 2 - 2021 - pp. 127-148

Universidad de la Frontera - Chile 


\section{Referencias bibliográficas}

ADORNO, T. \& HORKHEIMER, M. (2007). Dialéctica de la Ilustración. Ediciones Akal.

CABELlO, C. (2015). Prólogo a Gabriela Mistral. En J. Concha, Gabriela Mistral (pp. 1524). Ediciones Alberto Hurtado.

CASTILlO, A. (2014). El desorden de la democracia: Partidos políticos de mujeres en Chile. Palinodia.

CONCHA, J. (2015). Gabriela Mistral. Ediciones Alberto Hurtado.

LÉVI-STRAUSS, C. (2010). A Oleira Ciumenta. Edições 70.

PALEOTTI, G. (2002). Discorso intorno alle immagini sacre e profane (1582). Libreria editrice vaticana.

POZO, D. (2015a). La importancia de Gabriela Mistral hoy. En J. Concha, Gabriela Mistral (pp.25-30). Ediciones Alberto Hurtado. (2015b). Por la Humanidad Futura: Antología Política de Gabriela Mistral. La Pollera Ediciones.

QUEZADA, J. (2014). Gabriela Mistral: Antología de Poesía y Prosa. Fondo de Cultura Económica. 